\title{
COVID-19 Vaccine and Vaccination Misinformation and Disinformation: Repositioning Our Role as Educators in Pandemic Times
}

\author{
Michael B. Cahapay ${ }^{1 *}$
}

${ }^{1}$ College of Education, Mindanao State University, General Santos City, PHILIPPINES

*Corresponding Author: mbcahapay@up.edu.ph

Citation: Cahapay, M. B. (2022). COVID-19 Vaccine and Vaccination Misinformation and Disinformation: Repositioning Our Role as Educators in Pandemic Times. European Journal of Environment and Public Health, 6(1), em0095. https://doi.org/10.21601/ejeph/11498

\begin{abstract}
ARTICLE INFO
Received: 10 Jul. 2021

Accepted: 18 Nov. 2021

ABSTRACT

We often encounter misleading claims, some of which have potential to influence decisions we make in our daily lives. Many people from all walks of life, even the most schooled, fall prey to the traps of misinformation and disinformation. How do such delusions enter our knowledge base and inform our public opinions and actions? I discuss in this editorial article the bases that underlie the issues of misinformation and disinformation that plague current COVID-19 vaccine and vaccination efforts. Such issues have a philosophical base anchored on the information processing theories and psychological base linked to our cognitive tendencies. I reflect in the end on our primary responsibility as teachers in these issues. I conclude that metacognition or a knowledge of our thinking, if we mindfully dare to pursue it, can help stimulate an enlightened perspective to ourselves that, with our vast influence as educators, may illuminate the perspectives of others.
\end{abstract}

Keywords: misinformation, disinformation, COVID-19 vaccine, COVID-19 vaccination, philosophy, psychology, education

\section{Dear Editor,}

As educators, we are in a better but critical position where our views reach vast influence. Thus, it is dangerous if we feed information without evaluation. The words that we hear and read are supposed to stimulate our minds and sharpen our judgments. However, values today seemed to have been bamboozled as misinformation and disinformation slither like snakes into the core of human morality. Misinformation is false, erroneous, or misleading information that is communicated regardless of an intention to deceive (Lazer et al., 2018). Disinformation is a subclass of misinformation that is deliberately deceptive, e.g., malicious hoaxes and propaganda (Woolley and Howard, 2016). These two prevalent issues have often been linked with the idea of fake news, defined as fictitious information that imitates news media content in form but not in organizational intent (Lazer et al., 2018).

With the anticipated continued COVID-19 vaccine and vaccination rollout, the issues of misinformation and disinformation in these challenging times are crucial in the government efforts and our public lives. Recent studies found that an increased acceptance of the COVID-19 fake news was consistently linked to a decreased willingness to get the COVID-19 vaccine and vaccination (e.g., Roozenbeek et al., 2020). This claim has been recently supported by pieces of evidence showing a moderate to a high level of COVID-19 vaccine and vaccination hesitancy in different selected samples, including the sample of teachers (e.g., Cahapay, 2021).

First, such issues of misinformation and disinformation, including the phenomenon of fake news, trace a philosophical base anchored on the information processing theories. An early major theory I learned to explain the information processes of the mind is the Spinozan Model. The ancient philosopher Baruch Spinoza believed that when the human mind is faced with new information, that information is initially comprehended and universally believed as true and later rejected if found false. From this model, I infer that information is processed in two stages: comprehension, which involves the initial acceptance of information as generally true; and evaluation, which involves deliberation of information, and rejection if found false.

Moreover, the Spinozan hypothesis states that "interruption would prevent subjects from unbelieving the assertions that they automatically accepted on comprehension and would thus cause subjects to report such false assertions as true" (Gilbert et al., 1990: 224). Hence, whether true or false, some information remains exclusively true as interruptions may prevent it from reaching evaluation. To put these stages in the context of misinformation and disinformation in the 
current emergency, when people initially read fake news e.g., COVID-19 infection can be prevented by consuming methanol (Forrest, 2020) or COVID-19 vaccine will turn a person into a zombie (Reuters, 2020), the mind initially encodes this information as correct and it can only be rejected if later found incorrect. For me, this hypothesis puts the brain in a vulnerable position, and it can be dangerous as risking the lives of people.

An equally important model to view information processing is offered by another great philosopher Rene Descartes. His model often referred to as Cartesian Model, posited that when the brain is presented with new information, that information is first comprehended, then assessed to see whether the information is true or false. Comparing and contrasting it to the former model, I see two similar but more defined stages of information processes: comprehension, which involves awareness purely without value acceptance; and evaluation, which consists of the deliberation if the information is true or false.

Based on the Cartesian model, researchers believe that we use familiarity to infer truth (Skurnik et al., 2005). Take note that from the model above, there is a clear distinction between comprehension and evaluation. Applied to misinformation and disinformation that are rampant in this time of COVID-19 emergency, this phenomenon works because of inferential reconstruction; information is forgotten after it has been encoded. The mind constructs only an inference, usually where false is interchanged or misunderstood as true. This is because the judgment in the evaluation stage is based just on familiarity this time.

Beyond the grasp of the two classical models explaining misinformation and disinformation, there is another question that needs to be probed. Considering the current COVID-19 emergency, the problem of misinformation and disinformation is more profound than how our brains process information. The general problem with those classical models is that they limit cognitive faculties of perception, consciousness, and judgment. So, what goes with our cognitive faculties when we have the slightest hint that something is false but we still choose to believe it and even justify it and spread it? This question is more personal and raises a moral concern, which in turn, opens a can of worms.

I found a social psychology concept as an answer: motivated reasoning. It is the concept that humans are motivated to accept whatever confirms their opinions. If a person is motivated to believe undesirable aspects about a person, he is more likely to trust outrageous tales about that person that might not always be true. Over time, motivated reasoning can lead to a false social consensus. This should explain the prevalent case today why people who are too loyal to their political ideologies e.g., anti-Chinese, anti-West groups choose to spread misinformation and disinformation e.g., the COVID-19 as a bioweapon engineered in a laboratory (Owen, 2020) or COVID-19 vaccines as a way to implant chips in the human body (Ningtyas, 2021).

O'Leary (2001) described motivated reasoning as an emotion-biased decision-making phenomenon in social psychology. This term describes the role of motivation in cognitive processes such as decision making and attitude change in several paradigms, including cognitive dissonance reduction, beliefs about others on whom our outcomes depend; and evaluation of evidence related to our personal outcomes. This is "a form of implicit emotion regulation in which the brain converges on judgments that minimize negative and maximize positive affect states associated with threat to or attainment of motives" (O'Leary, 2001: 1947).

Another concept as an answer is naive realism, which helps explain the chasm in our political discourse: instead of agreeing to disagree with opponents, humans tend to disgrace them. It is also why some are quick to label any report that challenges their worldview as fake when theirs is suppler than they realize. This provides a basis for cognitive biases so prevalent amid the COVID-19 emergency including selective reporting and even defending the misinformation and disinformation.

Lee and Ward (1995) have outlined three interrelated assumptions that make up naive realism. They argue that these assumptions are supported by a long line of thinking in social psychology, along with several empirical studies. According to their model, people believe that they see the world objectively and without bias; expect that others will come to the same conclusions, so long as they are exposed to the same information and interpret it rationally; and assume that others who do not share the same views must be ignorant, irrational, or biased.

As teachers, we have a greater sphere of influence on what others think, act, and feel incredibly in these trying periods of the COVID-19 crisis. At some point, we suffer from how our brains are already wired, hence exclude some grains. At another point, we inject some form of deeply wired instincts, which may send different signals to others. While we cannot escape from all the tendencies of our imperfect brain, our responsibility of first order is to gain personal insight into how we can use the philosophy and psychology underpinning the issues of misinformation and disinformation to our advantage. Thus, our convictions must be coupled with a study of how our brain works and its complex wires. All these philosophical and psychological contemplations remind us two things: that we need to continually evaluate what information goes through our minds and be careful about the validity of this information that we share. These forms of metacognition or knowledge of how we think, if we dare to pursue them, can stimulate personal and social growth to ourselves and other people around our circles and beyond.

Funding: No external funding is received for this article.

Declaration of interest: The author declares that no competing interests.

Ethics approval and consent to participate: Not applicable.

Availability of data and materials: All data generated or analyzed during this study are available for sharing when appropriate request is directed to corresponding author. 


\section{REFERENCES}

Cahapay, M. B. (2021). To get or not to get: Examining the intentions of Philippine teachers to vaccinate against COVID-19. Journal of Human Behavior in the Social Environment.

https://doi.org/10.1080/10911359.2021.1896409

Forrest, A. (2020). Coronavirus: 700 dead in Iran after drinking toxic methanol alcohol to 'cure COVID-19'. Independent. Available at https://www.independent.co.uk/news/world/ middle-east/coronavirus-iran-deaths-toxic-methanolalcohol-fake-news-rumours-a9487801.html

Gilbert, D. T., Krull, D. S. and Malone, P. S. (1990). Unbelieving the unbelievable: Some problems in the rejection of false information. Journal of Personality and Social Psychology, 59(4), 601-613. https://doi.org/10.1037/0022-3514.59. 4.601

Lazer, D. M. J., Baum, M. A., Benkler, Y., Berinsky, A. J., et al. (2018). The science of fake news. Science, 359(6380), 10941096. https://doi.org/10.1126/science.aao2998

Lee, R. and Ward, A. (1995). Naive realism: Implications for social conflict and misunderstanding. In T. Brown, E. S. Reed and E. Turiel (Eds.), Values and knowledge. Lawrence Erlbaum Associates.

Ningtyas, I. (2021). Indonesia battles spread of vaccine misinformation. Available at: https://www.aa.com.tr/en/ asia-pacific/indonesia-battles-spread-of-vaccinemisinformation/2124319
O’Leary, A. (2001). Teaching tip sheet: Motivated reasoning. Available at: https://www.apa.org/pi/aids/resources/ education/reasoning

Owen, J. (2020). Fake news jeopardising chances of COVID-19 vaccine success, study warns. Available at: https://www.prweek.com/article/1697855/fake-newsjeopardising-chances-covid-19-vaccine-success-studywarns

Reuters. (2020). Fact check: A vaccine did not turn characters in the movie 'I Am Legend' into zombies. Available at: https://www.reuters.com/article/uk-factcheck-vaccine-iam-legend-zombies-idUSKBN28S23W

Roozenbeek, J., Schneider, C. R., Dryhurst, S., Kerr, J., et al. (2020). Susceptibility to misinformation about COVID-19 around the world. Royal Society Open Science, 7(10), 201199. https://doi.org/10.1098/rsos.201199

Skurnik, I., Yoon, C., Park, D. and Schwarz, N. (2005). How warnings about false claims become recommendations. Journal of Consumer Research, 31(4), 713-724. https://doi.org/10.1086/426605

Woolley, S. C. and Howard, P. N. (2016). Political communication, computational propaganda, and autonomous agents. International Journal of Communication, 10(2016), 4882-4890. 